\title{
Distinguishing between primary infection and reinfection with rubella vaccine virus by IgG avidity assay in pregnant women
}

R. Hamkar, ${ }^{1}$ S. Jalilvand, ${ }^{1}$ M.H. Abdolbaghi, ${ }^{2}$ K.N. Jelyani, ${ }^{1}$ A. Esteghamati, ${ }^{3}$ A. Hagh-goo, ${ }^{4}$ T. Mohktari-Azad ${ }^{1}$ and R. Nategh ${ }^{1}$

$$
\begin{aligned}
& \text { التمييز بين العدوى الأولية وبين تجدّد العدوى بفيروس لقاح الحصبة الألمانية عن طريق تحليل رغابة الغلوبولين المناعي } \\
& \text { G } \\
& \text { رسول همكار، سمية جليلوند، محبوبة حاجي عبد الباقي، كرامت نوري جلياني، عبد الرضا استقامتي، آمنة حق كو، }
\end{aligned}
$$

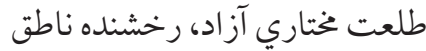

ABSTRACT During the mass measles/rubella vaccination campaign in 2003 in Iran, many pregnant women were vaccinated mistakenly or became pregnant within 1 month of vaccination. To distinguish pregnant women who were affected by rubella vaccine as primary infection from those who had rubella reinfection from the vaccine, serum samples were collected 1-3 months after the campaign from 812 pregnant women. IgG avidity assay showed that $0.3 \%$ of the women had no rubella-specific IgG response; $14.4 \%$ had low-avidity anti-rubella IgG and were therefore not immune to rubella before vaccination; $85.3 \%$ had high-avidity antirubella IgG and were regarded as cases of reinfection.

Distinction entre la primo-infection et la réinfection par le virus du vaccin contre la rubéole grâce au test d'avidité des IgG chez les femmes enceintes

RÉSUMÉ Lors de la campagne de vaccination de masse contre la rougeole et la rubéole réalisée en 2003 en Iran, de nombreuses femmes enceintes ont été vaccinées par erreur ou se sont trouvées enceintes un mois après la vaccination. Afin de distinguer les cas de primo-infection par le vaccin contre la rubéole des cas de réinfection par ce vaccin, des échantillons de sérum ont été prélevés sur 812 femmes enceintes pendant une période comprise entre un et trois mois après la campagne. La mesure de l'avidité des IgG rubéoliques a montré que $0,3 \%$ des femmes n'avaient pas de réponse ; $14,4 \%$ avaient des IgG antirubéoliques de faible avidité et n'étaient donc pas immunisées avant la vaccination ; et $85,3 \%$ avaient des IgG antirubéoliques de forte avidité et pouvaient donc être considérées comme des cas de réinfection.

\footnotetext{
${ }^{1}$ School of Public Health; ${ }^{2}$ Imam Khomeini Hospital, Tehran University of Medical Sciences, Tehran, Islamic Republic of Iran (Correspondence to R. Hamkar: rhamkar@sina.tums.ac.ir). ${ }^{3}$ Disease Management Centre, Ministry of Health and Medical Education, Tehran, Iran. ${ }^{4}$ Rasool Akram Hospital, Iran University of Medical Sciences, Tehran, Iran.
}

Received: 24/05/06; accepted: 27/07/06

المجلة الصحية لشرق المتوسط، منظمة الصحة العالمية، المجلد الخامس عشر، العدد (، 9 • ب 


\section{Introduction}

Rubella, if acquired during the first trimester of pregnancy, carries a $90 \%$ risk of congenital malformations for the fetus, called congenital rubella syndrome (CRS) [1]. Prevention of CRS is the main goal of rubella vaccination and 2 approaches are recommended [2]: prevention of CRS only through vaccination of adolescent girls and/ or women of childbearing age, and elimination of both rubella and CRS through universal vaccination of infants with/without mass campaigns, surveillance and ensuring immunity in women of childbearing age [3].

There is a significant burden of disease globally as a result of CRS, and the World Health Organization (WHO) recommends that countries incorporate rubella vaccine into their vaccination programmes if possible [4-8].

Rubella vaccination in pregnancy caries a theoretical risk of CRS if the vaccine is administered during or just before pregnancy $[3,9]$. This is because the rubella vaccine is a live attenuated virus that is able to replicate in vaccinees and can cross the placenta to infect the fetus in about $2 \%$ of susceptible mothers. However, there is no evidence that fetal infection with the vaccine virus is harmful $[9,10]$. Prospective registries in several countries have identified no infants with CRS born to known seronegative women who received rubella vaccine within 3 months of conception; thus, the observed risk is zero [3]. Based on data from these registries, and using the upper $95 \%$ confidence limit of the binomial distribution, the maximum estimated risk is $0.6 \%$ among women vaccinated within 3 months of conception with the Cendehill or RA27/3 rubella strains, and the maximum estimated risk is $2.5 \%$ among susceptible women vaccinated within the first 2 months of pregnancy with the RA27/3 strain. These maximum theoretical risks remain lower than the $3 \%$ risk of a major congenital malformation in the general population. It has been suggested that there will always be an upper maximum theoretical risk greater than zero, no matter how large a study is carried out. It is believed, therefore, that vaccination in pregnancy can never be positively recommended $[9,10]$.

During the mass campaign of measles/ rubella (MR) vaccination in December 2003 in the Islamic Republic of Iran, a large number of pregnant women received MR vaccine mistakenly or became pregnant soon after vaccination. Based on existing data about the epidemiological features of rubella in the Islamic Republic of Iran, around $80 \%-90 \%$ of the above-mentioned women may have been immune against rubella before vaccination [11-13]. Therefore, they may have experienced a rubella reinfection by the vaccine strain, and a relatively small proportion of them $(10 \%-20 \%)$ may have developed primary rubella infection from the vaccine strain. Although cases of CRS due to rubella reinfection, even by wild-type rubella virus, are very rare [14], it was seen as necessary to distinguish between pregnant women who were affected by rubella vaccine as primary infection and those who had rubella reinfection from the vaccine. Evidence of reinfection would be accepted if a patient who had pre-existing rubella antibodies showed a significant rise of $\operatorname{IgG}$ antibody titre or a rubella-specific IgM response, or both [1]. The IgM response is typically weak, but may sometimes be strong.

In this study, we used IgG avidity assay to determine the immune response among pregnant women receiving rubella vaccine in the mass vaccination campaign in the Islamic Republic of Iran in order to separate reinfection cases with high-avidity IgG

المجلة الصحية لشرق المتوسط، منظمة الصحة العالمية، المجلد الخامس عشر، العدد (، 9 ·. 
antibodies from primary infections with low-avidity response. Despite the lack of any reports of CRS due to rubella vaccine, there is a theoretical risk of CRS. Therefore, susceptible women who experience primary infection from rubella vaccine should be followed up.

\section{Methods}

\section{Background to the study}

Prior to the mass vaccination programme extensive information about the contraindications to vaccination during pregnancy were released by the media and married women were advised at the time of vaccination about the risks of becoming pregnant for up to 1 month after vaccination. While 108000 pregnant women did not participate in vaccination during the mass campaign, many pregnant women did receive the MR vaccine. Most were in the early days of pregnancy at the time of vaccination and therefore did not know about their pregnancy, while some women, against advice, became pregnant soon after vaccination. Following the mass campaign, 2 major hospitals in Tehran, Imam Khomeini and Rasool Akram hospitals, and our laboratory were prepared to advise pregnant women who had been inadvertently vaccinated. A total of 812 pregnant women were referred to the above centres and participated in the study.

\section{Sample}

The study sample was 812 pregnant women aged 15-25 years old [mean 21.9 (standard deviation 2.4) years] who had received MR vaccine mistakenly or became pregnant after vaccination. The MR vaccine contained measles Edmonston Zagreb strain and rubella RA27/3 strain (Serum Institute of India Ltd, Hadepsar, Pune, India). Serum samples were collected 1-3 months after the MR mass campaign in December 2003, and stored at $-80^{\circ} \mathrm{C}$.

\section{Commercial enzyme immunoassays}

Serum samples were tested by both rubellaspecific IgM and IgG enzyme-linked immunoassay (EIA). The differential assay of rubella high-avidity and low-avidity IgG antibodies can be used as a potent assay to distinguish between primary and secondary immune response. This assay is gaining popularity as a diagnostic method for the assessment of the time of infection [15-17]. However, the rubella IgM assay may not be an appropriate test to distinguish between the primary and secondary immune responses, because detection of rubellaspecific IgM alone cannot be considered absolute proof of a recent primary infection. IgM response after primary infection may be prolonged, lasting up to several years. Furthermore, in some reinfections, rubella IgM is detectable [15].

The commercial kits used were the Enzygnost anti-rubella virus IgM and Enzygnost anti-rubella virus IgG (Dade Behring, Marburg, Germany). All assay protocols, cut-offs and interpretation of results were carried out according to the manufacturer's instructions.

For the anti-rubella IgM assay 2 local (in-house) preparations of weak and strong positive IgM standards were included as external controls in every EIA run.

The avidity of $\mathrm{IgG}$ for rubella virus was measured by a protein-denaturing EIA where the antibodies were first allowed to bind to the rubella virus antigen, followed by elution by buffer with and without 35 $\mathrm{mM}$ diethylamine $[15,18,19]$. Each sample was tested at 2 replicates and a single serum dilution (1:200) was applied to each replicate. After incubation for 1 hour, test plates were washed 4 times, and then 1 replicate 
was soaked for 5 min in washing buffer and the other replicate for $5 \mathrm{~min}$ in washing buffer containing $35 \mathrm{mM}$ diethylamine. Fresh buffers were applied and this step was carried out 2 more times. The plates were then washed 4 times with washing buffer. Then the test was continued according to the kit procedure. The remaining specific antibody was then detected using optical density (OD), and an avidity index (AI) was calculated as follows:

$$
\mathrm{AI}(\%)=\frac{\mathrm{OD}_{\text {wells soaked with } 35 \mathrm{mM} \text { DEA }}}{\mathrm{OD}_{\text {wells soaked with wash buffer }}} \times 100
$$

Four serum sample controls were used at each testing: strong high-avidity anti-rubella IgG antibody; moderate-avidity anti-rubella IgG antibody; low-avidity anti-rubella IgG antibody; and an anti-rubella IgG-negative serum sample.

The rubella IgG avidity cut-off point was $53 \%$ of that calculated previously in another study using well-defined panels of sera as primary and secondary immune response to rubella vaccine in order to determine low- and high-avidity rubella-specific IgG responses [15].

\section{Statistical analysis}

The parameters calculated included sensitivity, specificity and positive and negative predictive values along with corresponding 95\% confidence intervals (CI) in the differential diagnosis of rubella primary and secondary immune responses for both rubella IgM EIA and rubella IgG avidity assay. The chi-squared test was used to determine the statistical difference between the parameters of the 2 measurements. The laboratory findings and personal data from study groups were also compared using the chi-squared test. The non-parametric Jonckheere-Terpstra statistical method [20] was employed to test for trend of avidity index values at the $1 \mathrm{st}, 2 \mathrm{nd}$, 3rd and 4 th months after vaccination. $P$-value $<0.05$ was considered statistically significant.

\section{Results}

\section{Rubella IgG avidity assay results}

A total of 117 cases (14.4\%) had lowavidity anti-rubella $\mathrm{IgG}$ and 2 cases $(0.3 \%)$ did not have any rubella-specific IgG, while 693 cases $(85.3 \%)$ had high-avidity antirubella IgG (Table 1).

The rate of low-avidity response was significantly related to age (Table 2) $(P<0.001)$. Low-avidity response was detected in $21.4 \%$ of women aged $\leq 20$ years and high-avidity rubella IgG in $78.6 \%$, while low-avidity response was detected in only $12.0 \%$ of women aged $>20$ years, and $88.0 \%$ exhibited high-avidity response to rubella vaccine.

\section{Rubella IgM-EIA results}

Rubella-specific IgM was detected in 90 cases $(76.9 \%)$ of primary infection (low-

\begin{tabular}{|c|c|c|c|c|c|c|c|}
\hline \multirow[t]{2}{*}{$\begin{array}{l}\text { Rubella } \\
\text { IgM }\end{array}$} & \multicolumn{2}{|c|}{$\begin{array}{l}\text { Low-avidity } \\
\text { rubella IgG }\end{array}$} & \multicolumn{2}{|c|}{$\begin{array}{l}\text { High-avidity } \\
\text { rubella IgG }\end{array}$} & \multicolumn{2}{|c|}{$\begin{array}{c}\text { Rubella IgG } \\
\text { negative }\end{array}$} & \multirow[t]{2}{*}{ Total } \\
\hline & No. & $\%$ & No. & $\%$ & No. & $\%$ & \\
\hline Positive & 90 & 97.8 & 2 & 2.2 & 0 & 0.0 & 92 \\
\hline Negative & 27 & 3.7 & 691 & 96.0 & 2 & 0.3 & 720 \\
\hline Total & 117 & 14.4 & 693 & 85.3 & 2 & 0.3 & 812 \\
\hline
\end{tabular}

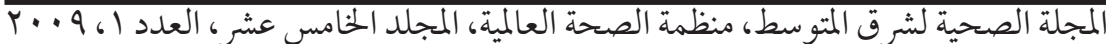


Table 2 Distribution of rubella IgG avidity assay results by age for pregnant women accidentally immunized with rubella

\begin{tabular}{lccccc}
\hline $\begin{array}{l}\text { Age } \\
\text { (years) }\end{array}$ & $\begin{array}{c}\text { Low-avidity anti-rubella IgG } \\
\text { No. }\end{array}$ & $\%$ & \multicolumn{2}{c}{ High-avidity anti-rubella IgG } & Total \\
\hline$\leq 20$ & 46 & 21.4 & 169 & 78.6 & 215 \\
$>20$ & 71 & 12.0 & 524 & 88.0 & 595 \\
Total & 117 & 14.4 & 693 & 85.6 & 810 \\
\hline
\end{tabular}

avidity anti-rubella $\mathrm{IgG})$, and not detected in 27 cases $(23.1 \%)$ (Table 1$)$. In the immune group, with high-avidity anti-rubella $\mathrm{IgG}$, anti-rubella IgM was not detected in 691 cases $(99.7 \%)$.

\section{Comparison of rubella IgM-EIA with avidity assay}

The rubella IgM-EIA was compared with the rubella IgG avidity assay. The sensitivity and specificity were determined using low-avidity anti-rubella IgG response (primary infection) and high-avidity antirubella $\mathrm{IgG}$ response (reinfection) cases (Tables 1 and 3).

\section{Effect of time of sample collection on rubella IgG avidity maturation}

In the low-avidity IgG group, IgG avidity gradually increased over time; the mean avidity index was $6.12 \%$ in the 1 st month, then increased to $20.82 \%, 27.16 \%$ and $38.03 \%$ in the $2 \mathrm{nd}, 3 \mathrm{rd}$ and 4 th months respectively (Table 4 and Figure 1). This trend was highly significant in the lowavidity sera group $(P<0.001)$. However, our results showed no significant trend among avidity indices in the 1st, 2nd, 3rd and 4th months among the high-avidity sera group $(P=0.617)$.

\section{Discussion}

Rubella vaccination should be avoided in pregnancy because of the theoretical (but never demonstrated) teratogenic risk [10]. Data were available from the United States of America, the United Kingdom, Sweden and Germany on 680 live births to susceptible women who were vaccinated inadvertently 3 months before or during pregnancy with HPV-77, Cendehill or RA27/3 vaccines. None of the infants was born with CRS. However, a small theoretical risk of $0.5 \%$ (upper $95 \% \mathrm{CI}=0.5 \%$ ) cannot be ruled out. Limiting the analysis to the 293 infants born to susceptible mothers vaccinated 1-2 weeks before conception or 4-6 weeks after conception, the maximum theoretical risk is $1.3 \%$ [9]. Although it is reassuring that no child was born with symptoms attributable to CRS, it is not appropriate to suggest that rubella vaccine is safe in early pregnancy [21].

Table 3 Sensitivity, specificity and predictive values of rubella IgM enzyme immunoassay (EIA) compare to rubella IgG avidity assay

\begin{tabular}{|c|c|c|c|c|}
\hline \multirow[t]{2}{*}{ Test } & Sensitivity & Specificity & $\begin{array}{c}\text { Positive } \\
\text { predictive value }\end{array}$ & $\begin{array}{c}\text { Negative } \\
\text { predictive value }\end{array}$ \\
\hline & $\%(95 \% \mathrm{Cl})$ & $\%(95 \% \mathrm{Cl})$ & $\%(95 \% \mathrm{Cl})$ & $\%(95 \% \mathrm{Cl})$ \\
\hline Rubella IgM-EIA & 76.9 (69.3-84.5) & $99.7(99.3-100.0)$ & $97.8(96.6-98.6)$ & $96.2(95.1-97.7)$ \\
\hline
\end{tabular}

$\mathrm{Cl}=$ confidence interval. 
According to existing data, about $80 \%-90 \%$ of fertileage women are immune to rubella before vaccination [11-13]. Therefore, a relatively small proportion of inadvertently vaccinated pregnant women $(10 \%-20 \%)$ may develop primary rubella infection from the vaccine strain. As documented reports of CRS by rubella reinfection, even by wild-type rubella virus, are very rare [14], distinction between primary infection and reinfection by the vaccine is necessary.

In the present study, IgG avidity assay was used to determine the immune response against rubella vaccine among pregnant women. The most critical part of this assay is the precise calculation of the cut-off point for differentiating low-avidity IgG from high-avidity IgG. A cut-off point equal to $53 \%$ of that previously calculated was applied to separate rubella low-avidity IgG from highavidity $\operatorname{IgG}[15]$.

The laboratory findings indicated $14.7 \%$ of the women were not immune against rubella virus before vaccination, and $14.4 \%$ of them experienced a primary infection with the rubella vaccine strain. However, $85.3 \%$ of cases had high-avidity anti-rubella $\mathrm{IgG}$, suggesting they were immune before vaccination and their response to rubella vaccine should be regarded as a secondary immune response. These results demonstrate that most women are immune at childbearing age. The findings also confirm previous reports of rubella immunity status in the Islamic Republic of Iran. The rate of immunity against rubella infection in our country was reported to range from $83 \%$ to $94.6 \%$ [11-13]. Thus around $5.4 \%-17 \%$ of Iranian women of childbearing age are susceptible to rubella infection, which means that there is a considerable risk of rubella infection during pregnancy, which could lead to CRS. According to these results, rubella vaccination was deemed necessary for elimination of CRS in the Islamic Republic of Iran. Mass vaccination in December 2003 provided appropriate immune coverage among women of childbearing age; only $0.3 \%$ of women failed to take up the vaccine. It is essential that vaccination against rubella enter into the policy of vaccination and that all of infants should be vaccinated against rubella for maintenance of this coverage.

Based on our results, the difference between primary infection and reinfection was statistically significant between the 2 age groups. Among the age group $\leq 20$ years old, $21.4 \%$ experienced primary infection and $78.6 \%$ showed

المجلة الصحية لشرق المتوسط، منظمة الصحة العالمية، المجلد الخامس عشر، العدد (، 9 +. 


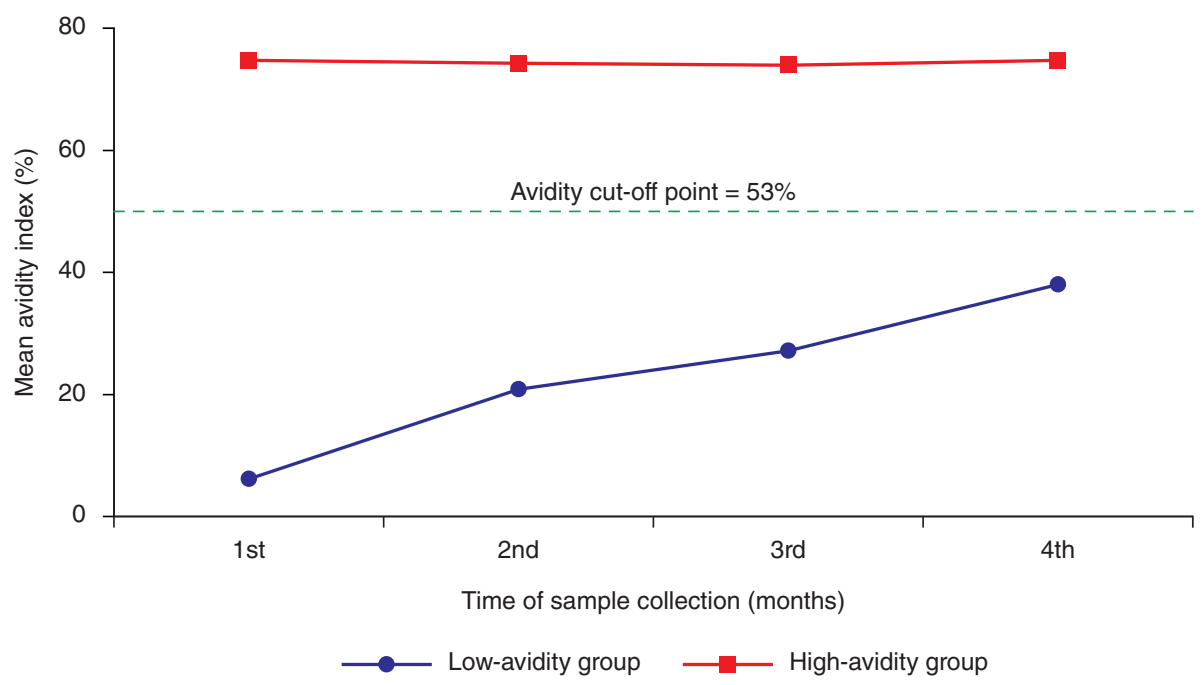

Figure 1 Rubella IgG avidity maturation by time of sample collection in low- and high-avidity groups

reinfection following rubella vaccination. However, among the $>20$ years age group, $11.8 \%$ had primary infection and $88.2 \%$ experienced reinfection or no immune response from the rubella vaccine strain. This difference suggests that immunity against rubella infection increases with age.

Our sampling continued up to 4 months after vaccination and indicated that the avidity index values of the low-avidity group had an increasing trend by the time of sample collection, but were lower than the avidity cut-off point, even up to 4 months. In contrast, for the high-avidity group sera, the avidity index values were not affected by the timing of sampling: mean avidity indices were constant over the period of sample collection. So, according to these results, measurement of rubella-specific IgG avidity can distinguish primary infection from reinfection up to 4 months after vaccination. In one study it was observed that all samples had an avidity index $<30 \%$ up to 3 months and a considerable increase was ob- served in avidity after 4 months [22]. That result demonstrated that primary infection can be differentiated from reinfection for up to 4 months. In another study, the time course of maturation of rubella IgG avidity after acute infection was demonstrated [23]. Well-characterized serial samples from 15 patients with acute rubella were tested and followed up for 5 months after the onset of rash. A high-avidity index (> 60\%) was not observed until 13 weeks after infection.

In our study, rubella-specific IgM antibody was detected in $76.9 \%$ of sera containing low-avidity IgG, but $23.1 \%$ of sera tested by IgM-EIA provided negative results. While the sensitivity of IgM-EIA for diagnosing primary rubella infection was $76.9 \%$, IgM-EIA did not have the appropriate sensitivity to distinguish between primary and secondary infections. However, IgM-EIA has appropriate specificity $(99.7 \%)$ for determining negative cases and it can detect non-primary rubella cases, which again confirms previously reported 
findings [15]. Previously, the sensitivity and specificity of 7 commercial rubellaspecific IgM kits were assessed, and it was shown that the sensitivity of most kits was within the range of $66.4 \%-78.9 \%$ (median $73.9 \%$ ). The specificity of these kits was estimated to be $85.6 \%-96.1 \%$ (median $92.6 \%$ ). The sensitivity and specificity of IgM-EIA for detection of rubella infection was shown by Behring's indirect EIA kit to be $75.9 \%$ and $98.7 \%$, respectively [5]. In another study it was shown that the percentage of rubella-specific IgM-positive sera decreased from $100 \%$ at $15-28$ days after the onset of infection through $71 \%$, $28 \%$ and $9 \%$ at $1-2,2-3$ and $3-4$ months, respectively. After 4 months, all sera were negative for rubella specific IgM antibody. However, low-avidity specific IgG was detected in all of the sera taken at 3 months. At 3-4 months $91 \%$ and at 5-7 months $21 \%$ of sera still showed low-avidity [24].

Our study shows that the positive predictive value and negative predictive value of IgM-EIA were $97.6 \%$ and $96.4 \%$ respectively. When the prevalence of rubella is low, such as in countries with high rubella vaccination coverage, the positive predic- tive value of IgM testing decreases such that there is a significant risk of false positive results, and additional confirmation tests are therefore required $[5,15,25]$. The measurement of rubella-specific IgG avidity is a specific and sensitive method for the serological diagnosis of recent primary infection, and provides the distinction between primary infection and possible reinfection $[15,18]$.

It is essential that a correct diagnosis of primary rubella can be achieved for the management of pregnant women with a recent rash or contact with a rubelliform rash illness [26]. With the introduction and widespread use of the rubella vaccine, it is likely that, with time, relatively few cases of rubella infection during pregnancy will be primary infection and more will be rubella reinfection $[14,27]$. Therefore, detection of IgM alone cannot differentiate primary infection from reinfection. For these cases, the measurement of $\operatorname{IgG}$ avidity is very useful, since, in the case of recent primary infection, IgG is low-avidity and in the case of reinfection, $\operatorname{IgG}$ is high-avidity $[15,18,24,28,29]$.

\section{References}

1. Best $\mathbf{J M}$ et al. Fetal infection after maternal reinfection with rubella: criteria for defining reinfection. British medical journal, 1998, 299:773-5.

2. Control and prevention of rubella: evaluation and management of suspected outbreaks, rubella in pregnant women, and surveillance for congenital rubella syndrome. Morbidity and mortality weekly reports, 2001, 50(RR12):1-23.

3. Report of a meeting on preventing congenital rubella syndrome: immunization strategies, surveillance needs. Geneva, 12-14 January 2000. Geneva,
World Health Organization, 2000 (WHO/ $\mathrm{V} \& \mathrm{~B} / 00.10)$

4. Cutts FT et al. Control of rubella and congenital rubella syndrome in developing countries. Part 1. Burden of disease from congenital rubella syndrome. Bulletin of the World Health Organization, 1997, 75(1):55-68.

5. Robertson SE et al. Control of rubella and congenital rubella syndrome (CRS) in developing countries, Part 2: Vaccination against rubella. Bulletin of the World Health Organization, 1997, 75(1):69-80. 
6. Tipples $\mathrm{G}$ et al. Evaluation of rubella IgM enzyme immunoassays. Journal of clinical virology, 2004, 30(3):233-8.

7. Rubella vaccines: WHO position paper. Weekly epidemiological record, 2000, 75(20):161-72.

8. Preventing congenital rubella syndrome. Weekly epidemiological record, 2000, 75(36):290-5.

9. Notice to readers: Revised ACIP recommendation for avoiding pregnancy after receiving a rubella-containing vaccine. Morbidity and mortality weekly reports, 2001, 50(49):1117.

10. World Health Organization. Vaccination against rubella [website] (http://www.who. int/vaccines/en/rubella2.shtml, accessed 15 February 2008).

11. Doroudchi $M$ et al. Seroepidemiological survey of rubella immunity among three populations in Shiraz, Islamic Republic of Iran. Eastern Mediterranean health journal, 2001, 7(1-2):128-38.

12. Ganjooie TA, Mohammadi MM. The prevalence of antibodies against rubella in pregnant women in Kerman, Iran. Saudi medical journal, 2003, 24(11):1270-1.

13. Kabiri $M$, Moattari $A$. The rubella immunosurveillance of Iranian females: an indication of the emergence of rubella outbreak in Shiraz, Iran. Iranian journal of medical science, 1993, 18(3-4):134-7.

14. Aboudy $Y$ et al. Subclinical rubella reinfection during pregnancy followed by transmission of virus to the fetus. Journal of infection, 1997, 34:273-6.

15. Hamkar R et al. Assessment of IgM enzyme immunoassay and IgG avidity assay for distinguishing between primary and secondary immune response to rubella vaccine. Journal of virological methods, 2005, 130(1-2):59-65.

16. Bodéus M, Feyder S, Goubau P. Avidity of IgG antibodies distinguishes primary from non-primary cytomegalovirus infection in pregnant women. Clinical and diagnostic virology, 1998, 9:9-16.

17. Korhonen $\mathrm{MH}$ et al. A new method with general diagnostic utility for the calculation of immunoglobulin $\mathrm{G}$ avidity. Clinical and diagnostic laboratory immuonology, 1999, 6(5):725-8.

18. Gutiérrez $\mathrm{J}$ et al. Reliability of low-avidity $\lg G$ and of $\lg A$ in the diagnosis of primary infection by rubella virus with adaptation of a commercial test. Journal of clinical laboratory analysis, 1999, 13(1):1-4.

19. Thomas HI, Morgan-Capner P. Rubellaspecific IgG1 avidity: a comparison of methods. Journal of virological methods, 1991, 31:219-28.

20. Hollander M, Wolfe DA. Nonparametric statistical methods. Chapter 6. London, John Wiley, 1999:202-12.

21. Tookey P. Pregnancy is a contraindication to rubella vaccination still [letter]. British medical journal, 2001, 322:1489.

22. Hedman $\mathrm{K}$ et al. Maturation of immunoglobulin $G$ avidity after rubella vaccination studied by an enzyme linked immunosorbent assay (avidity-ELISA) and by haemolysis typing. Journal of medical virology, 1989, 27(4):293-8.

23. Bottiger B, Jensen PI. Maturation of rubella IgG avidity over time after acute rubella infection. Clinical and diagnostic virology, 1997, 8:105-11.

24. Thomas $\mathrm{HI}$ et al. Persistence of specific IgM and low-avidity specific IgG1 following primary rubella. Journal of virological methods, 1992, 39:149-55.

25. Best JM et al. Interpretation of rubella serology in pregnancy-pitfalls and problems. British medical journal, 2002, 325:147-8.

26. Inouye $S$ et al. Changes in antibody avidity after virus infections: detection by an immunosorbent assay in which a mild 
protein-denaturing agent is employed. Journal of clinical microbiology, 1984, 20(3):525-9.

27. Thomas HIJ, Charlett A, Cubie HA. Specific $\lg _{1}$ avidity maturation after rubella vaccination: A comparison with avidity maturation after primary infection with wild rubella virus. Serodiagnosis and immunotherapy in infectious disease, 1995, 7:7580.

28. Enders G, Knotek F. Rubella IgG total antibody avidity and IgG subclass-specific antibody avidity assay and their role in the differentiation between primary rubella and rubella reinfection. Infection, 1989, 17(4):218-26.

29. Thomas HIJ, Morgan-Capner P. Rubellaspecific IgG subclass avidity ELISA and its role in the differentiation between primary rubella and rubella reinfection. Epidemiology of infection, 1988, 101(3):591-8.

\section{Measles and rubella laboratory network}

The global measles and rubella laboratory network was developed based on the successful model of the global polio laboratory network. As of 2008, 679 laboratories have been established in 164 countries. Many of these laboratories are also responsible for laboratory-based surveillance of other vaccine preventable diseases in their countries. Rubella surveillance is often integrated with measles surveillance as the WHO measles case definition also captures rubella cases. Many countries administering rubella vaccine also take advantage of the combination vaccine presentation of measles and/or mumps. The confirmation of rubella cases is very similar to measles. The standard procedure recommends use of an IgM ELISA assay performed on a single serum sample. Most countries follow a procedure of testing measles negative samples for rubella. Rubella virus detection is more challenging than for measles, but when successful, sequence information can be utilized for the same molecular epidemiological purposes as for measles.

Further information about the Measles and rubella laboratory network can be found at: http://www.who.int/immunization_monitoring/laboratory_measles/en/index.html 